\title{
Severe Trauma of Uterus and the Right Limb during a Road Accident at the Department of Obstetrics and Gynecology of the Teaching Hospital Souro Sanou of Bobo-Dioulasso: A Case Report and Review of Literature
}

\author{
Bambara Moussaํ, Ouedraogo Issa ${ }^{2}$, Diallo Malick³, Yaro Biessan ${ }^{4}$, Komboïgo Evelyne ${ }^{4}$ \\ ${ }^{1}$ Department of Obstetrics and Gynecology, University Joseph Ki-Zerbo, CUHSS, Bobo-Dioulasso, Burkina Faso \\ ${ }^{2}$ Service of Obstetrics and Gynecology, University Joseph Ki-Zerbo, CHR-OHG, Ouayigouya, Burkina Faso \\ ${ }^{3}$ Department of Surgery, Teaching Hospital Souro Sanou, Bobo-Dioulasso, Burkina Faso \\ ${ }^{4}$ Teaching Hospital Souro Sanou, Bobo-Dioulasso, Burkina Faso \\ Email: mousbambara@yahoo.fr, oued_issa2002@yahoo.fr,malikijallo@yahoo.com, biessanyaro@gmail.com, \\ evelynekomboigo@yahoo.fr
}

How to cite this paper: Moussa, B., Issa, O., Malick, D., Biessan, Y. and Evelyne, K. (2021) Severe Trauma of Uterus and the Right Limb during a Road Accident at the Department of Obstetrics and Gynecology of the Teaching Hospital Souro Sanou of Bobo-Dioulasso: A Case Report and Review of Literature. Open Journal of Obstetrics and Gynecology, 11, 1836-1842.

https://doi.org/10.4236/ojog.2021.1112170

Received: November 5, 2021

Accepted: December 27, 2021

Published: December 30, 2021

Copyright $\odot 2021$ by author(s) and Scientific Research Publishing Inc. This work is licensed under the Creative Commons Attribution International License (CC BY 4.0).

http://creativecommons.org/licenses/by/4.0/ (c) (i) Open Access

\begin{abstract}
The authors reported a case of trauma with uterus rupture at 35 weeks gestation with fetal death in uterus with a trauma of the right limb injuries during a serious road accident. Aim: the aim is to show the increasing of road accident with the motorized tricycle and their many risks for pregnant woman. Case Presentation: our patient was thrown from the back cargo of a motorized tricycle (three-wheeled vehicle) after a collision with a truck in a rural area from $150 \mathrm{~km}$ to Bobo-Dioulasso. She sustained a closed abdominal injury and a severe right lower limb open injury. At admission in our department in the Teaching Hospital, she was conscious, shocked with hemodynamic instability, including low blood pressure $(75 / 52 \mathrm{mmHg})$, rapid heart rate (140 pulses per minute), rapid breath rate (40 per minute), and cold extremities. Abdominal examination was painful with uterine hypertonia, $28 \mathrm{~cm}$ height uterus, and no fetal heart heartbeat. A laparotomy in urgency revealed a rupture of the uterus fundus with a dead fetus. A conservative surgical treatment was performed. An open trauma to the right limb was managed by the orthopedists with a good outcome. Conclusion: Accident trauma during pregnancy is becoming more and more frequent with the increase in means of transport in urban and inter urban areas. The transport ways of the pregnant woman must take into account her safety and that of the fetus.
\end{abstract}




\section{Keywords}

Road Accident, Uterus Rupture, Fetal Death, Right Limb Injury, Good Outcome

\section{Introduction}

Road accidents affect $5 \%$ to $7 \%$ of pregnancies and are the leading cause of maternal death from non-obstetrical causes between 14 and 44 years old [1]. The traumatic causes of uterus rupture are rare and concern less than $1 \%$ of pregnant women involved in serious road accidents. It's about a life-threatening obstetric emergency involving the maternal fetal prognosis. The management is most often multidisciplinary in the event of associated lesions [1] [2]. We report a case of uterus rupture from traumatic origin and a deep fascio-cutanous wound on the back of the right foot and the right limb during serious road accident.

\section{Observations}

A 22 year-old woman G2 P2, evacuated on May 21 $1^{\text {st }}, 2021$ from a primary level hospital of Kourouma, from $150 \mathrm{~km}$ to Bobo-Dioulasso, after a road traffic accident. She was thrown from the back cargo of a motorized tricycle (three-wheeled vehicle) after a collision with a truck. She sustained a closed abdominal injury and a severe right lower limb open injury. At admission, she was conscious, shocked with hemodynamic instability, including low blood pressure (75/52 $\mathrm{mmHg}$ ), rapid heart rate (140 pulses per minute), rapid breath rate (40 per minute), and cold extremities. Abdominal examination was painful with uterine hypertonia, $28 \mathrm{~cm}$ height uterus, and no fetal heart heartbeat.

Genital examination showed bleeding through the vulva. The use of speculum confirmed the bleeding endo-uterine origin. The cervix was long posterior and dehiscent. The fetal presentation was high, mobile, and podalic. Ultrasonography (US) showed a dead 34 weeks fetus, an abruptio placenta, and a collection in the Douglas pouch.

At the right limb, we noticed soft tissue injuries in the leg and the foot without any associated osteoarticular or neurovascular lesion. The right foot injury was skin degloving at the dorsum aspect exposing extensors tendons. The leg injury was above the fascia of the sural triceps at the posterior aspect.

Massive Blood transfusion and multidisciplinary surgical procedures were undertaken. The laparotomy revealed a $1200 \mathrm{cc}$ intraperitoneal hemorrhage, a $7 \mathrm{~cm}$ uterus fundus rupture, and an intrauterine dead fetus. The fetus and the placenta extraction were easily performed through the uterine rupture. The fetus weighed 2600 grams and the placenta 400 grams. The uterus was repaired in three layers, the abdominal cavity was irrigated with saline solution, and the abdominal wall was closed with suction. The limb injury required debridement, sutures, and above-knee posterior splinting. The outcome was good (Figures 1-3). 


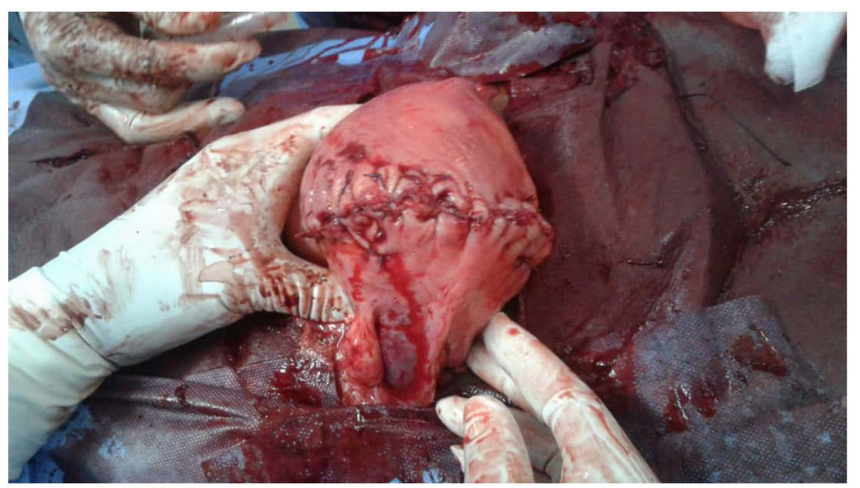

Figure 1. Intra-operative aspect of the Uterus reparation. The origin: teaching hospital Sourô Sanou.

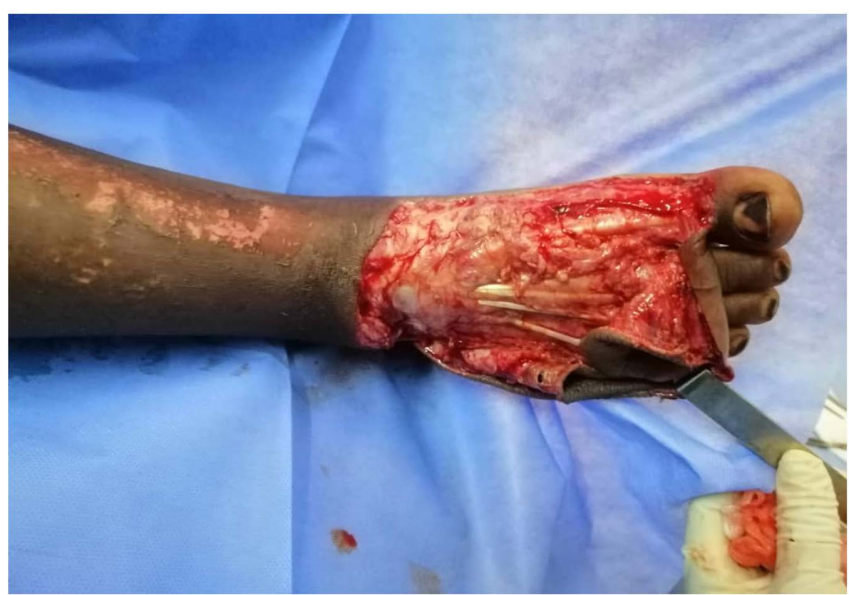

Figure 2. Clinical aspect of the right lower limb. Pre-operative aspect of the foot injury. The origin: teaching hospital Sanou Souro.

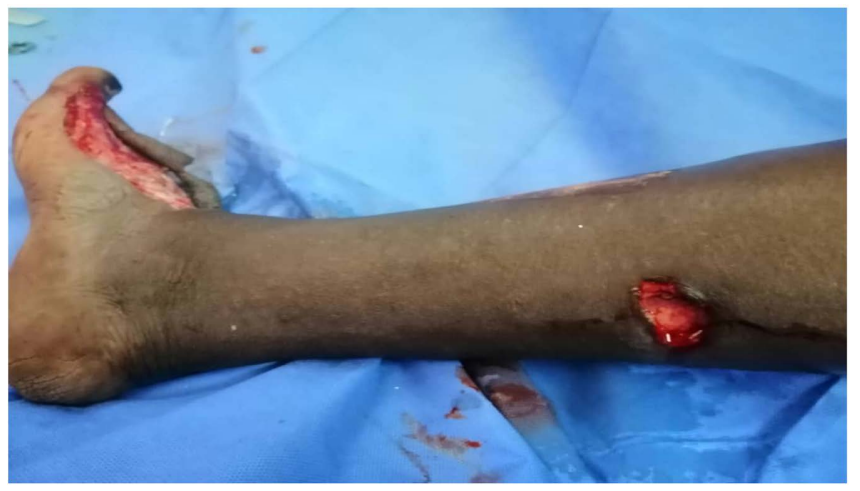

Figure 3. Deep wound of the right limb. The origin: teaching hospital Sourô Sanou.

\section{Discussion}

\subsection{Epidemiology}

In developing countries two or three wheeled, motorcycle and vehicles collisions caused more than $80 \%$ of too much trauma during pregnancy. The other causes 
of trauma are represented by domestic assault and violence [3] [4]. We observe since a decade, a serious increase of tricycles in developing countries where they are used as means of transport. In Taiwan a 10 year study from 2004 to 2014 shows that traumas complicated $6 \%$ to $7 \%$ of pregnancies and mainly represented the causes of maternal non obstetrical deaths [5]. The uterine ruptures from traumatic origin during violent accident would be at the origin of $10 \%$ of maternal deaths and $100 \%$ of fetus deaths [6] [7].

The uterus ruptures from obstetrical origin are the most frequent in developing countries and mainly in Africa [8] [9] [10] [11]. These ruptures occur most often during labor and the most common etiology are the pelvic fetal disproportion, dystocia presentations and the abuse use of oxytocics.

\subsection{Clinical Aspects of Traumatic Uterus Rupture}

The injury mechanism may be a direct (abdominal contusion, perforating trauma) or indirect trauma due to maternal deceleration and maternal blood pressure variation [1]. Wearing a seat belt during transport in a vehicle would reduce the rate of the obstetrical complications [12] [13]. Our patient did not wear any seat belt and was thrown from the tricycle to fall on the abdomen forward.

The symptomatology in case of uterus rupture most often results in severe abdominal pain with a defense, general maternal signs of hypovolemic shock, conjunctival scale, accelerated pulses and cold extremities. A shopping dullness of the blanks may be found in case of abundant hemoperitoneum with a fetus and its placenta in the abdomen [14] [15] [16]. According to the term of occurrence of the accidents, the most frequent obstetrical complications are miscarriages, the labor prematurity and the rupture of the membranes [1].

Uterine rupture is a serious complication of road accidents occurring especially in the $2^{\text {nd }}$ and $3^{\text {th }}$ trimester of pregnancy, period where the uterus is exposed to traumas [17]. The seat is most often fundus as it was the case in our patient. Serious complications involving the materno-fetal prognosis are linked to uterus rupture, abruptio placenta [15]-[20]. Non obstetrical complications during road accidents may concern abdominal contusion, the spleen rupture, and the liver or ureteral lesions [21] [22] [23].

The fetal mortality rate after non-penetrating trauma varies from $3.4 \%$ and $38 \%$ depending on the studies and it varies from $67 \%$ to $75 \%$ in the event of abruptio placenta [24] [25]. The risk of fetal life correlates with the severity of trauma or maternal death [20]. Prehospital care and reception in surgical emergencies is fundamental to reduce hospital morbidity and materno-fetal mortality [1].

The hospital care is poorly conducted in under medicalized countries. The conditions for picking up the wounded, non-medical transport are often of poor quality or even non-existent.

The consequences are that the patients evacuated most often over long distances are greeted in a state of shock with often many cases of death on admission. 
Once in reception facilities, emergency actions are taken and then the call for help.

- A quick initial assessment.

- Ensure free airways.

- Take two venous routes to fight against the state of shock with the contribution of solicited crystalloids, blood products and their derivatives.

- A quick biological assessment (blood group, blood count, renal check-up, blood sugar).

- The contribution of imagery proves to be invaluable in the treatment (abdominal ultrasound, $\mathrm{x}$-ray and abdomino-pelvic tomodensitometry).

- An urgent intervention is carried out while continuing the resuscitation especially in the event of uterus rupture of abruptio placenta. In the case of our patient, it was about a rupture of the uterus fundus over $7 \mathrm{~cm}$, intrauterine fetus with a fetal head insuring the hemostasis of the uterus fundus.

- After fetal extractor, we performed a hysterorrhaphy of the uterine fundus in three ways, recommending a prophylactic cesarean section for subsequent pregnancies because she was a young patient, desiring motherhood.

- A hysterectomy may be performed if the uterus is severely sagging or has incontrollable bleeding from the uterus. Yakasai I [15] and Wondimagegnehu SW [16] have performed total hysterectomy whereas Smith [26], Ortiz Mendota [26] and Noffat SE [27] reported cases of subtotal hysterectomy to pregnant woman during serious road traffic accident.

\section{Conclusions}

Accident trauma during pregnancy is becoming more and more frequent with the increase in means of transport in urban and inter urban areas. The transport ways of the pregnant woman must take into account her safety and that of the fetus.

In many developing countries, the disorder of road traffic, the dilapidated state of the means of transport and the non-use of seat belts are the cause of many accidents.

\section{Conflicts of Interest}

The authors declare no conflicts of interest regarding the publication of this paper.

\section{References}

[1] Vaysse, C., Mignot, F.J., Benezech, P. and Parant, O. (2007) Traumatic Uterine Rupture: A Rare Complication of Motor Vehicle Accidents during Pregnancy. A Case Report. Journal de Gynécologie Obstétrique et Biologie de la Reproduction, 36, 611-614. https://doi.org/10.1016/j.jgyn.2007.05.008

[2] Geremew, A., Miteku, A.L. and Mihiretu, K. (2017) Maternal and Fetal Outcomes of Uterine Rupture and Factors Associated with Maternal Death Secondary to Uterine Rupture. BMC Pregnancy and Childbirth, 17, Article No. 117. 
https://doi.org/10.1186/s12884-017-1302-Z

[3] Rowe, T.F., Lafayette, S. and Cox, S. (1996) An Unusual Fetal Complication of Traumatic Uterine Rupture. Journal of Emergency Medicine, 14, 173-176.

https://doi.org/10.1016/0736-4679(95)02110-8

[4] Murphy, N.J. and Quinlan, J.D. (2014) Trauma in Pregnancy: Assessment, Management, and Prevention. American Family Physician, 90, 717-722.

[5] Mendez-Figueroa, H., Dahlke, J.D., Vrees, R.A. and Rouse, D.J. (2013) Trauma in Pregnancy: An Updated Systematic Review. American Journal of Obstetrics \& Gynecology, 209, 1-10. https://doi.org/10.1016/j.ajog.2013.01.021

[6] Pai, C.-W., Wiratama, B.S., Lin, H.-Y. and Chen, P.-L. (2021) Association of Traumatic Injury with Adverse Pregnancy Outcomes in Taiwan, 2004 to 2014. JAMA Network Open, 4, Article No. e217072. https://doi.org/10.1001/jamanetworkopen.2021.7072

[7] McLean, M.M., Shah, S., Shapiro, D. and Tilney, P.V.R. (2013) A 21-Year-Oldwoman with a Uterine Rupture. Air Medical Journal, 32, 230-232.

https://doi.org/10.1016/j.amj.2013.06.003

[8] Harrison, S.D., Nghiem, H.V. and, Shy, K. (1995) Uterine Rupture with Fetal Death Following Blunt Trauma. American Journal of Roentgenology, 165, 1452-1452. https://doi.org/10.2214/ajr.165.6.7484584

[9] Alemu, A.A., Bitew, M.S., Gelaw, K.A., Zeleke, L.B. and Kassa, G.M. (2020) Prevalence and Determinants of Uterine Rupture in Ethiopia: A Systematic Review and Meta-Analysis. Scientific Reports, 10, Article No. 17603.

https://doi.org/10.1038/s41598-020-74477-Z

[10] Biaye, B., Gassama, O., Faye Dieme, M.E., Niass, A., Mbodji, A., Dialo, M. and Diouf, A. (2018) Uterine Rupture Case Study at Kolda Regional Hospital Center. Gynecology \& Reproductive Health, 2, 1-3. https://doi.org/10.33425/2639-9342.1067

[11] Rajaonarison, J.J.C., Fenomanana, M.S., Rakotondraisoa, J.M. and Randriambelomanana, J.A. (2014) Uterine Rupture during Labour: Etiological Factors and Materno-Fetal Prognosis. International Journal of Reproduction, Contraception, $\mathrm{Ob}$ stetrics and Gynecology, 6, 8-12.

[12] Pearlman, M.D., Klinich, K.D., Schneider, L.W., Rupp, J., Moss, S. and Ashton-Miller, J. (2000) A Comprehensive Program to Improve Safety for Pregnant Women and Fetuses in Motor Vehicle Crashes: A Preliminary Report. American Journal of Obstetrics \& Gynecology, 182, 1554-1564. https://doi.org/10.1067/mob.2000.106850

[13] Cardoso, S.Q., Cardoso, M.F., Leite, J.C., Nascimento, E.R.N., Nascimento, M.H.R. and dos Santos, E.M.R. (2019) Maternal-Fetal Protection in Automobile Accidents and Reliability in the Use of Existing Safety Belts. International Journal of Advanced Engineering Research and Science, 6, 708-709. https://doi.org/10.22161/ijaers.6781

[14] Yakasai, I., Abdullahi, H.M. and Yusuf, M. (2012) Rupture of Gravid Uterus Following Road Traffic Accident. Literature Review and Case Report. WebmedCentral Obstetrics and Gynaecology, 3, 1-7.

http://www.webmedcentral.com/article view/3851

[15] Wondimagegnehu, S.W., Demisew, A. and Hailemariam, S. (2015) Uterine Rupture in Pregnancy Following Fall from a Motorcycle: A Horrid Accident in Pregnancy-A Case Report and Review of the Literature. Obstetrics and Gynecology, 2015, Article ID: 715180. https://doi.org/10.1155/2015/715180

[16] Touré, E.A., Aka, K.E., Konan, P., Koffi Koffi, A. and Olou, L. (2017) Traumatic Uterine Rupture Following a Traffic Accident: About a Case. Open Journal of $O b$ - 
stetrics and Gynecology, 7, 957-965. https://doi.org/10.4236/ojog.2017.79097

[17] Page, N., Roloff, K., Modi, A.P., Modi, A.P., Dong, F. and Neeki, M.M. (2020) Management of Placental Abruption Following Blunt Abdominal Trauma. Cureus, 12, Article No. e10337. https://doi.org/10.7759/cureus.10337

[18] Lien, C., Ali, A. and Culhane, J. (2016) Blunt Abdominal Trauma with Uterine Rupture and Fetal Demise. Trauma, 19, 219-221. https://doi.org/10.1177/1460408616681601

[19] Fabricant, S.P., Greiner, K.S. and Caughey, A.B. (2019) Trauma in Pregnancy and Severe Adverse Perinataloutcomes. The Journal of Maternal-Fetal \& Neonatal Medicine, 34, 3070-3074. https://doi.org/10.1080/14767058.2019.1678129

[20] Abu-Rmaileh, M., Jensen, H. and Katherine Kimbrough, M. (2020) Traumatic Bilateral Ureteral Tear in a Pregnant Woman after a Motor Vehicle Crash: A Case Report. Journal of Surgical Case Reports, 9, Article No. rjaa331. https://doi.org/10.1093/jscr/rjaa331

[21] Agboola, A.D., Osuala, P.C., Afuwape, O.O. and Omigbodun, A.O. (2020) Traumatic Splenic Rupture in Pregnancy with Favourable Pregnancy Outcome: Case Report. Tropical Journal of Obstetrics and Gynaecology, 37, 204-206. https://doi.org/10.4103/TJOG.TJOG 8419

[22] Abu-Rmaileh, M., Jensen, H. and Katherine Kimbrough, M. (2020) Traumatic Bilateral Ureteral Tear in a Pregnant Woman after a Motor Vehicle Crash: A Case Report. Journal of Surgical Case Reports, 9, Article No. rjaa331.

https://doi.org/10.1093/jscr/rjaa331

[23] Towery, R., English, T.P. and Wisner, D. (1993) Evaluation of Pregnant Women after Blunt Injury. The Journal of Trauma, 35, 731-735. https://doi.org/10.1097/00005373-199311000-00014

[24] Baerga-Varela, Y., Zietlow, S.P., Bannon, M.P., Harmsen, W.S. and Ilstrup, D.M. (2000) Trauma in Pregnancy. Mayo Clinic Proceedings, 75, 1243-1248. https://doi.org/10.4065/75.12.1243

[25] Smith, R.J. (1989) Avulsion of the Non-Gravid Uterus Due to Pelvic Fracture. Southern Medical Journal, 82, 70-73.

[26] Ortiz-Mendoza, C.M. and Fernandez-Carreno, A.J. (2004) Uterine Avulsion by Blunt Abdomino-Pelvic Trauma (in Spanish). Cirugía y Cirujanos, 72, 499-502.

[27] Moffatt, S.E., Goldberg, B., Kong, V.Y., Da Costa, J.-P., Smith, M.T.D., Bruce, J.L., Laing, G.L. and Clarke, D.L. (2020) Trauma in Pregnancy at a Major Trauma Center in South Africa S E Moffatt. South African Medical Journal, 110, 667-670. 